\title{
Influence of synthetic methods in the structure and dimensionality of coordination polymers
}

Iara M. L. Rosa,,$^{\dagger}$ Mayra C. S. Costa, ${ }^{\dagger}$ Bianca S. Vitto, ${ }^{\dagger}$ Laise Amorim, ${ }^{\dagger}$ Charlane C. Correa ${ }^{\S}$ Carlos B. Pinheiro ${ }^{\dagger}$ and Antonio C. Doriguetto ${ }^{\dagger}$

\begin{abstract}
† Laboratório de Cristalografia, Instituto de Química, Universidade Federal de Alfenas, AlfenasMG, Brazil. ${ }^{\ddagger}$ Laboratório de Cristalografia, Departamento de Física, Universidade Federal de Minas Gerais, Belo Horizonte-MG, Brazil. ${ }^{\S}$ Grupo de Pesquisa em Química dos Materiais Porosos, Departamento de Química, Universidade Federal de Juiz de Fora, Juiz de Fora - MG, Brazil.
\end{abstract}

E-mail: doriguetto@unifal-mg.edu.br

\section{Supporting Information}




\section{S1. Powder X-ray diffraction}



(a)

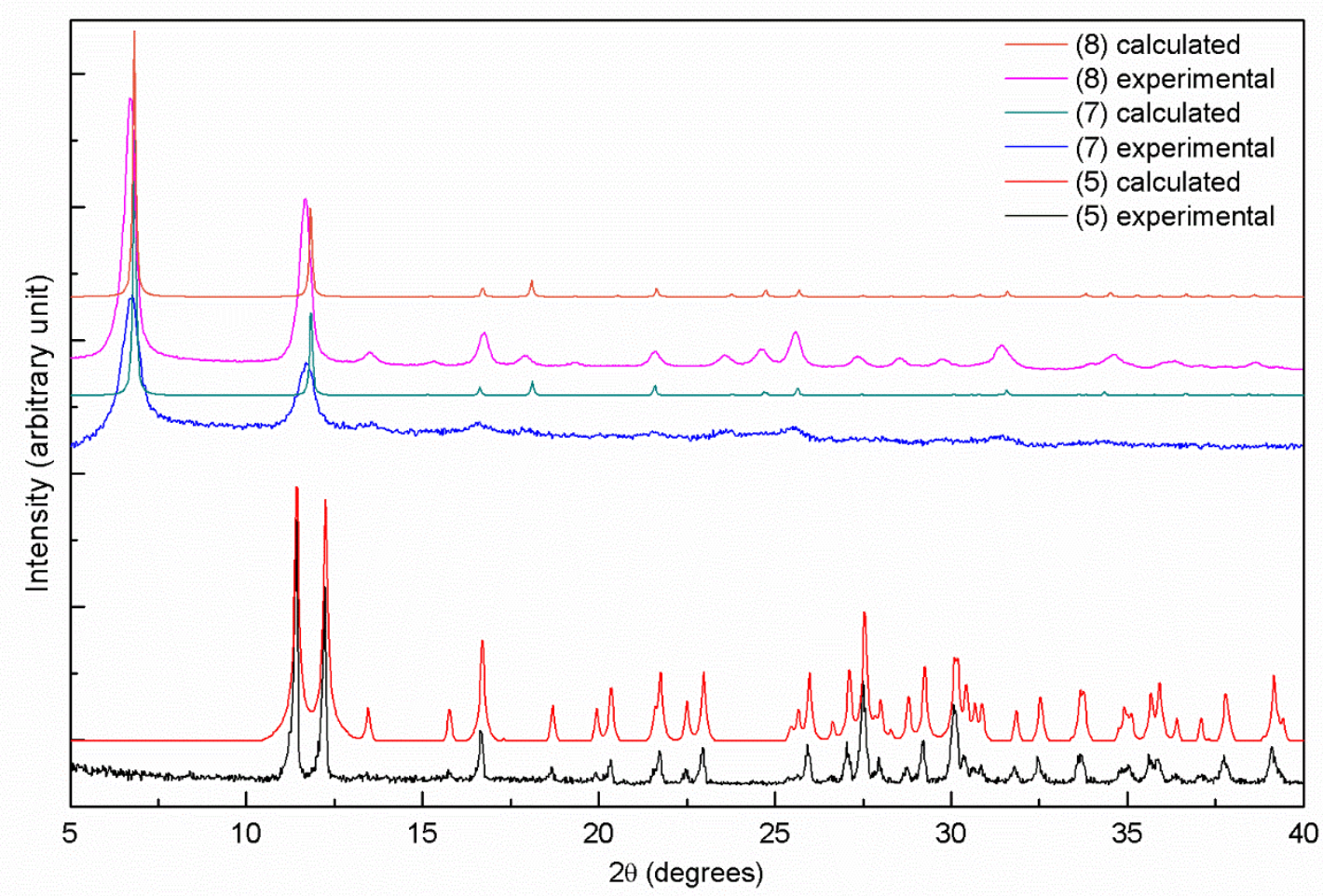

(b) 


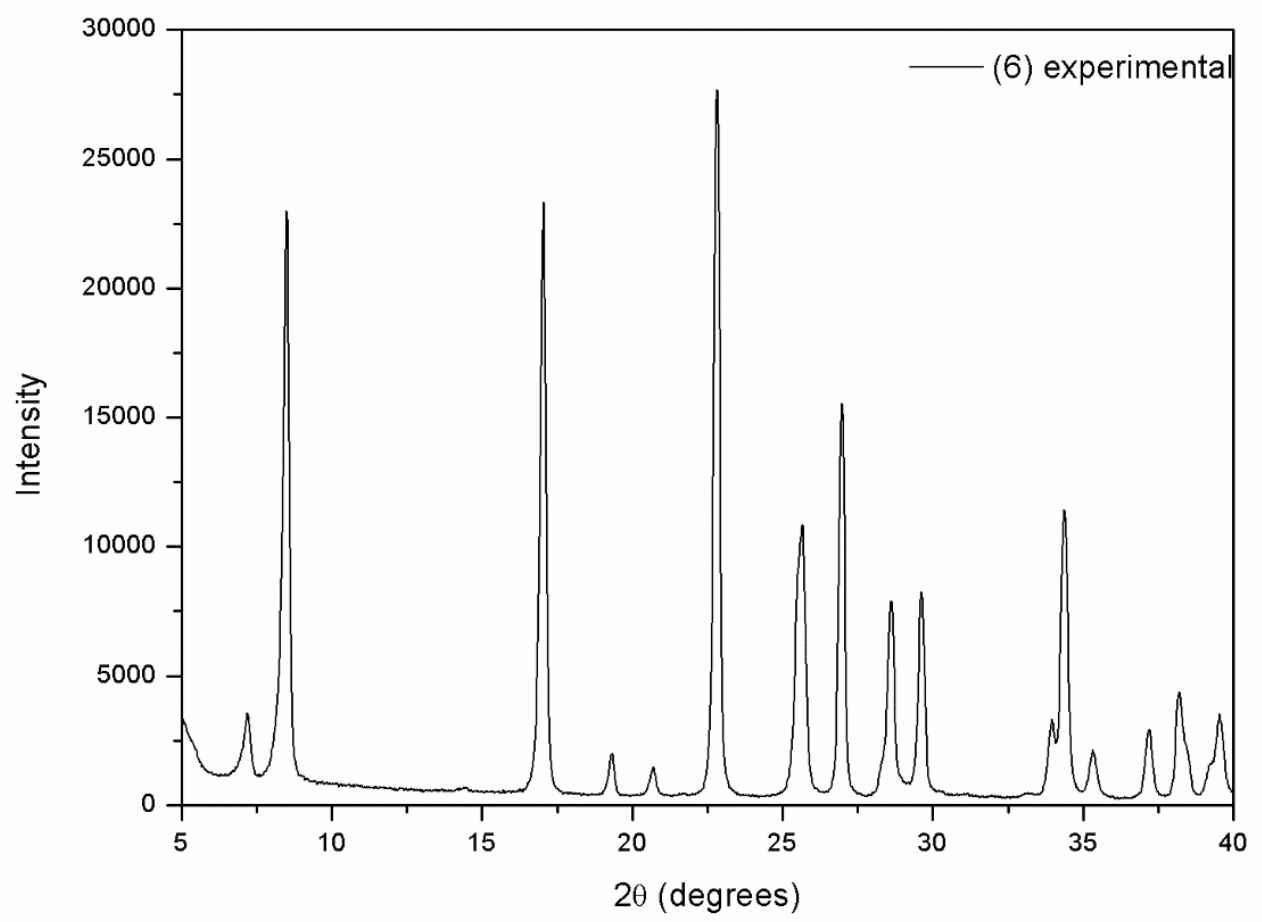

(c)

Figure S1. (a) Experimental and calculated PXRD patterns for the new products (1)-(4) obtained by method A (Unfortunately, due to the very low yield of (1), it was not possible to obtain its experimental PXRD pattern); (b) Experimental and calculated PXRD patterns for the known products (5), (7) and (8) obtained by method $\mathrm{B}\left(\mathrm{Co}_{2}(\mathrm{fum})_{2}\left(\mathrm{H}_{2} \mathrm{O}\right)_{4}(\mathrm{OH})_{2}\right] \cdot 2 \mathrm{H}_{2} \mathrm{O}-\mathrm{CSD}$ code: EWEBEN (reference 15); $\left[\mathrm{Co}_{2}(\mathrm{dobdc})\right]$-CSD code: NAVJAW (reference 16) and [Zn $\mathrm{n}_{2}$ (dobdc)] -CSD code: WIZDEP (reference 17)); (c) Experimental PXRD pattern for the new product (6) obtained by method B, for which the crystal structure was not determined due absence of single crystal good enough for Single Crystal XRD experiment.

\section{S2. Thermogravimetric analysis}

The thermal stabilities of the obtained CPs were examined using TGA, which was performed on the pure powder samples from $30^{\circ} \mathrm{C}$ to $1000{ }^{\circ} \mathrm{C}$ (Figure S2). It was not possible to analyze the thermal behavior of the compound (1) due to the very low yield of it. For (2), the TG/DTA curves show that, in the temperature range of $40{ }^{\circ} \mathrm{C}-215^{\circ} \mathrm{C}$, 
it's observed a weight loss of $47.00 \%$ corresponding to the loss of two moles of water and two moles of DMSO per formula unit (calc.: $51.72 \%$ ). The compound is stable up to $380{ }^{\circ} \mathrm{C}$, followed by a pyrolysis of the coordinated ligand, finishing at $486{ }^{\circ} \mathrm{C}$, with a weight loss of $26.76 \%$ (calc.: $26.37 \%)$. The residue is characterized as $\mathrm{ZnO}(21.65 \%$, calc.: $21.83 \%)$. For (3), in the temperature range of $85{ }^{\circ} \mathrm{C}-170{ }^{\circ} \mathrm{C}$, it's observed a weight loss of $23.23 \%$ corresponding to the loss of two moles of water and one mol of DMSO per formula unit (calc.: $25.52 \%$ ), followed by loss of $17.61 \%$ in the temperature range of $200^{\circ} \mathrm{C}-290^{\circ} \mathrm{C}$, correspondent to the loss of one mol of DMSO. The pyrolysis of the coordinated ligand occurs between $290{ }^{\circ} \mathrm{C}$ and $460{ }^{\circ} \mathrm{C}$, with loss of $41.66 \%$ (calc.: $40.26 \%)$. The residue is characterized as $\mathrm{CoO}(12.01 \%$, calc.: $16.75 \%)$. For (4), the first weight loss of $18.43 \%$ in the temperature range $40{ }^{\circ} \mathrm{C}-160{ }^{\circ} \mathrm{C}$, corresponds to the removal of two mols of water and two hydroxyl groups (calc.: 15.43 $\%$ ), followed by loss of $13.38 \%$ in the temperature range $165{ }^{\circ} \mathrm{C}-290{ }^{\circ} \mathrm{C}$, corresponding to the loss of four mols of methyl groups (calc.: $13.24 \%$ ). The loss of $25.17 \%$ in the temperature range of $290{ }^{\circ} \mathrm{C}-380^{\circ} \mathrm{C}$ corresponds the decomposition of the ligand (calc. $28.66 \%$ ), followed by a loss of $21.37 \%$ in the temperature range of $380{ }^{\circ} \mathrm{C}-465{ }^{\circ} \mathrm{C}$ corresponding of two mols of SO (calc.: $21.18 \%$ ). The residue was characterized as $\mathrm{ZnO}(17.55 \%$, calc.: $17.94 \%)$. For (5), the TGA plot clearly shows two steps of weight loss. The first loss of $19.15 \%$ that takes place between $50{ }^{\circ} \mathrm{C}$ and $215^{\circ} \mathrm{C}$ corresponds to the removal of six moles of terminal water per formula unit (calc.: $19.68 \%$ ). The second loss of $34.57 \%$ in the range of temperature of $240{ }^{\circ} \mathrm{C}$ and $350{ }^{\circ} \mathrm{C}$ represents the removal of one mol of bridge water and the decomposition of the anhydrous intermediate (calc. $33.89 \%$ ), producing $\mathrm{Co}_{3} \mathrm{O}_{4}$, that is stable up to $900{ }^{\circ} \mathrm{C}$. Over this temperature, the oxide is reduced to $\mathrm{CoO}$, representing the residue with $40.29 \%$ of the original mass (calc. $41.09 \%$ ). For (6), the first weight loss of $12.11 \%$ in the temperature range $40{ }^{\circ} \mathrm{C}-230{ }^{\circ} \mathrm{C}$, corresponds to the removal of two mols of hydroxyde group (calc. $12.19 \%$ ), followed by loss of $26.01 \%$ in the temperature range $290{ }^{\circ} \mathrm{C}-480{ }^{\circ} \mathrm{C}$, corresponding to the pyrolysis of the ligand (calc. $25.11 \%$ ). The 
residue was characterized as $\mathrm{ZnO}(58.13 \%$, calc.: $58.37 \%)$. As a proposal, we have the empirical formula $\mathrm{C}_{2} \mathrm{H}_{2} \mathrm{O}_{3} \mathrm{Zn}$. For (7), the first loss of $15.63 \%$ that takes place between $30{ }^{\circ} \mathrm{C}$ and $131{ }^{\circ} \mathrm{C}$ corresponds to the removal of three moles of water (two molecules coordinated to metal and one molecule solvating the whole structure) per formula unit (calc.: $14.68 \%$ ). The second loss of $52.52 \%$ in the range of temperature of $131^{\circ} \mathrm{C}$ and $449{ }^{\circ} \mathrm{C}$ represents the decomposition of the ligand (calc.: $48.94 \%$ ), producing $\mathrm{CoO}$. It reduces to $\mathrm{Co}$, characterized as residue with $26.74 \%$ of the original mass (calc.: $32.02 \%$ ). For (8), the first loss of $21.37 \%$ that takes place between $30{ }^{\circ} \mathrm{C}$ and $160{ }^{\circ} \mathrm{C}$ corresponds to the removal of five moles of water (two molecules coordinated to metal and three molecules solvating the whole structure) per formula unit (calc.: $21.75 \%$ ). The second loss of $44.63 \%$ in the range of temperature of $235{ }^{\circ} \mathrm{C}$ and $550{ }^{\circ} \mathrm{C}$ represents the decomposition of the ligand (calc.: $46.77 \%$ ), producing $\mathrm{Zn}$ as residue with $30.46 \%$ of the original mass (calc.: $31.60 \%$ ).



(a)

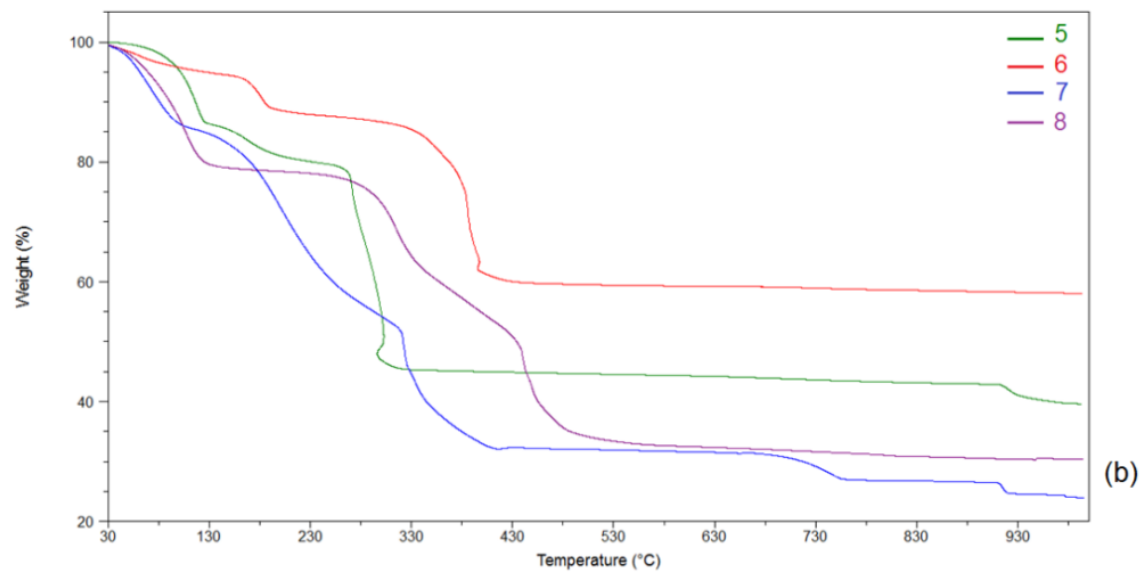

Figure S2. TGA curves of (a) compounds (2)-(4) and (b) (5)-(8). 
S3. Phase Transition by heating

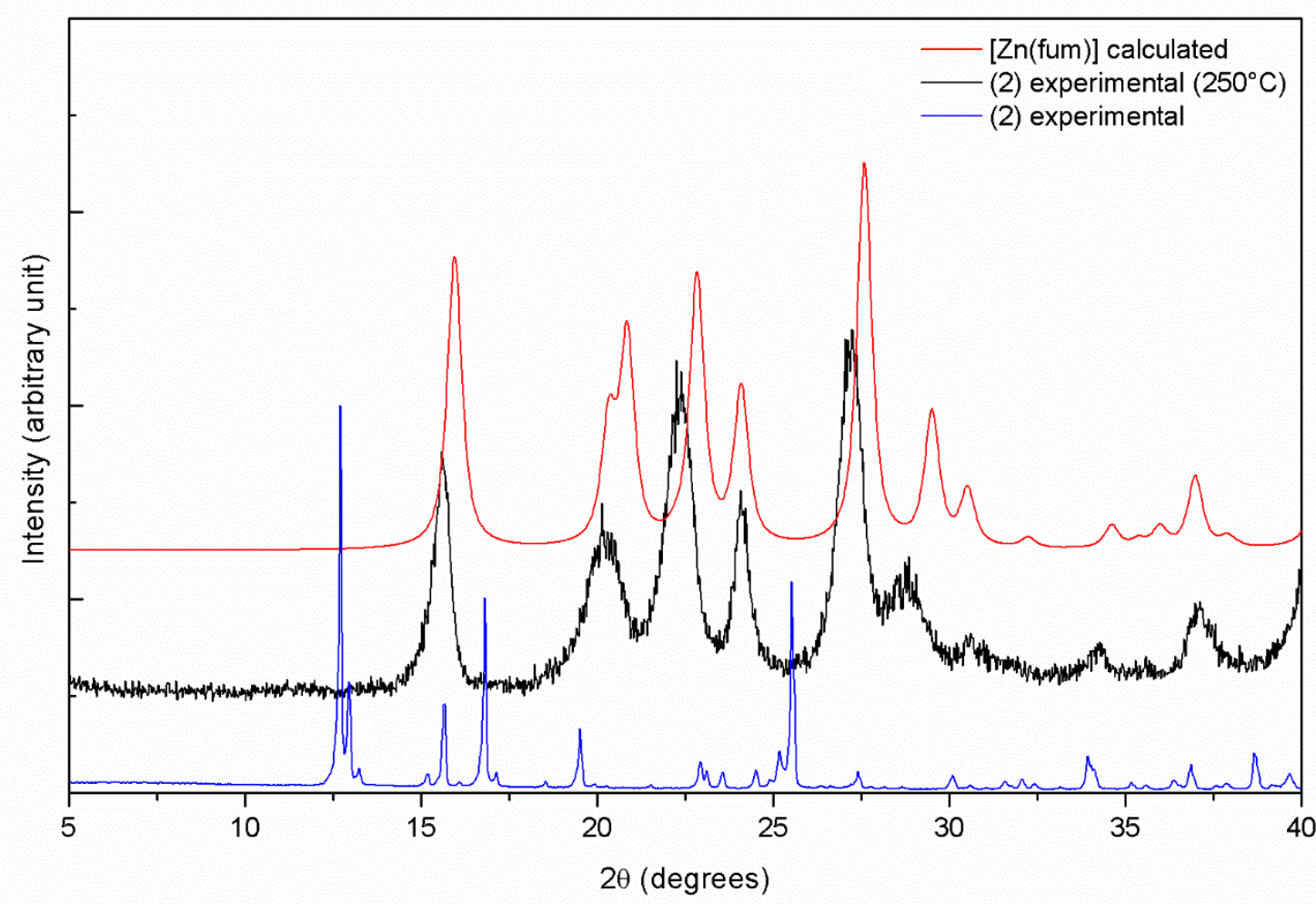

(a)
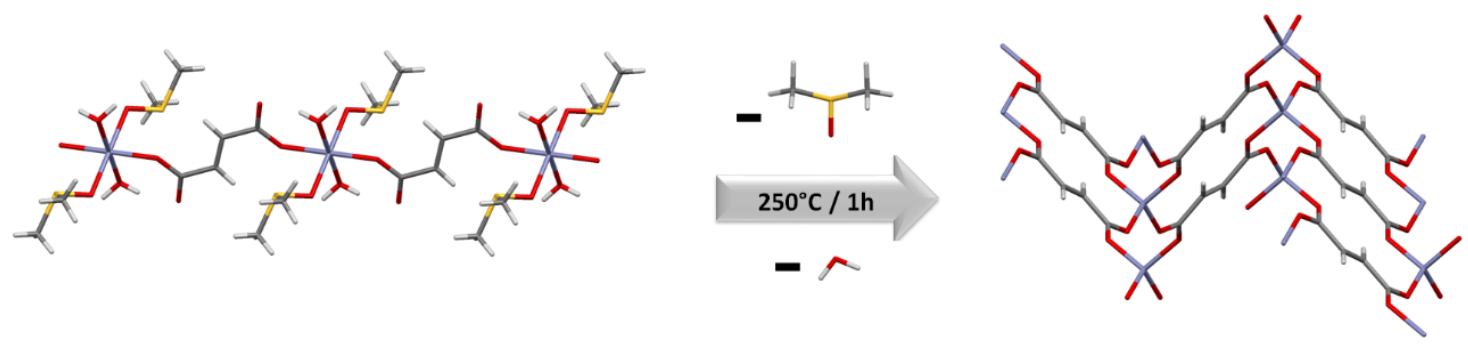

(b) 




(c)

Figure S3. (a) Experimental and calculated [Zn(fum)] - CSD code: VUJSAV (reference 25) PXRD patterns of the material obtained from the ex-situ heating of (2) at $250^{\circ} \mathrm{C}$. The calculated PXRD pattern of (2) was included in order to highlight the solid state reaction. (b) Representation of conversion of (2) in the compound [ $\mathrm{n}($ fum)] after heating. (c) Experimental PXRD patterns of the material obtained from the ex-situ heating of (4) at $250^{\circ} \mathrm{C}$. The calculated PXRD pattern of (4) was included in order to highlight the solid state phase transition.

\section{S3. Crystal data}

Table S1. M-O distances $(\AA)$ and $\mathrm{O}-\mathrm{M}-\mathrm{O}$ angles $\left(^{\circ}\right)$ for (1)-(4).

\begin{tabular}{|l|l|l|l|l|}
\hline & $(\mathbf{1})$ & $\mathbf{( 2 )}$ & $\mathbf{( 3 )}$ & $\mathbf{( 4 )}$ \\
\hline $\mathrm{M}-\mathrm{O}(\mathrm{L})$ & $2.0603(9)$ & $2.0490(17)$ & $2.089(2)$ & $2.0962(11)$ \\
\hline $\mathrm{M}-\mathrm{O}\left(\mathrm{H}_{2} \mathrm{O}\right)$ & $2.1148(10)$ & $2.1156(18)$ & $2.132(3)$ & $2.1095(12)$ \\
\hline $\mathrm{M}-\mathrm{O}(\mathrm{DMSO})$ & $2.1027(10)$ & $2.1330(17)$ & $2.076(2)$ & $2.1011(11)$ \\
\hline $\mathrm{O}(\mathrm{L})-\mathrm{M}-\mathrm{O}(\mathrm{DMSO})$ & $88.05(4)$ & $91.78(7)$ & $88.02(10)$ & $91.54(4)$ \\
\hline $\mathrm{O}\left(\mathrm{H}_{2} \mathrm{O}\right)-\mathrm{M}-\mathrm{O}(\mathrm{DMSO})$ & $89.54(4)$ & $90.34(7)$ & $93.83(10)$ & $86.41(4)$ \\
\hline $\mathrm{O}(\mathrm{L})-\mathrm{M}-\mathrm{O}\left(\mathrm{H}_{2} \mathrm{O}\right)$ & $89.55(3)$ & $88.89(7)$ & $91.91(10)$ & $91.83(4)$ \\
\hline
\end{tabular}




\begin{tabular}{|c|c|c|c|c|c|}
\hline & & $d(D-H)$ & $d(H \ldots A)$ & $d(D \ldots A)$ & $<(\mathrm{DHA})$ \\
\hline \multirow{5}{*}{1} & $\mathrm{O} 3-\mathrm{H} 8 \cdots \mathrm{O} 2^{\mathrm{a}}$ & $0.83(2)$ & $1.89(2)$ & $2.6849(13)$ & $161(2)$ \\
\hline & $\mathrm{O} 3-\mathrm{H} 9 \cdots \mathrm{O} 2^{\mathrm{b}}$ & $0.82(2)$ & $1.92(2)$ & $2.7350(31)$ & $174(2)$ \\
\hline & $\mathrm{C} 3-\mathrm{H} 4 \cdots \mathrm{O} 4$ & 0.960 & 2.607 & 3.498 & 154.63 \\
\hline & $\mathrm{C} 4-\mathrm{H} 6 \cdots \mathrm{O} 4$ & 0.960 & 2.548 & 3.451 & 156.81 \\
\hline & $\mathrm{C} 3-\mathrm{H} 3 \cdots \mathrm{O} 1$ & 0.960 & 2.628 & 3.458 & 144.91 \\
\hline \multirow{5}{*}{2} & $\mathrm{O} 3-\mathrm{H} 8 \cdots \mathrm{O} 2^{\mathrm{C}}$ & $0.81(4)$ & $1.90(4)$ & $2.688(3)$ & $164(4)$ \\
\hline & $\mathrm{O} 3-\mathrm{H} 9 \cdots \mathrm{O} 2^{\mathrm{d}}$ & $0.83(4)$ & $1.92(4)$ & $2.740(3)$ & $169(4)$ \\
\hline & C3-H5 $\cdots$ O4 & 0.960 & 2.609 & 3.499 & 154.34 \\
\hline & $\mathrm{C} 4-\mathrm{H} 3 \cdots \mathrm{O} 4$ & 0.960 & 2.543 & 3.446 & 156.69 \\
\hline & $\mathrm{C} 3-\mathrm{H} 6 \cdots \mathrm{O} 1$ & 0.960 & 2.627 & 3.461 & 145.49 \\
\hline \multirow{3}{*}{3} & $\mathrm{O} 4-\mathrm{H} 10 \cdots \mathrm{O} 1^{\mathrm{e}}$ & $0.85(6)$ & $2.06(6)$ & $2.888(4)$ & $166(5)$ \\
\hline & $\mathrm{O} 4-\mathrm{H} 9 \cdots \mathrm{O} 2$ & $0.94(5)$ & $1.75(5)$ & $2.651(3)$ & $161(5)$ \\
\hline & $\mathrm{O} 3-\mathrm{H} 8 \cdots \mathrm{O} 2^{f}$ & 0.82 & 1.84 & $2.554(3)$ & 145 \\
\hline \multirow{3}{*}{4} & $\mathrm{O} 4-\mathrm{H} 9 \cdots \mathrm{O} 2$ & $0.85(3)$ & $1.81(3)$ & $2.640(2)$ & 164(3) \\
\hline & $\mathrm{O} 3-\mathrm{H} 1 \cdots \mathrm{O} 2$ & 0.82 & 1.83 & $2.552(2)$ & 146 \\
\hline & $\mathrm{O} 4-\mathrm{H} 10 \cdots \mathrm{O} 1^{\mathrm{g}}$ & $0.81(3)$ & $2.09(3)$ & $2.882(2)$ & $168(2)$ \\
\hline \multicolumn{6}{|c|}{${ }^{a}-x+2,-y,-z+2 ;{ }^{b} x+1 / 2,-y+1 / 2, z+1 / 2 ;{ }^{c}-x+/ 2,-y,-z+2 ;{ }^{d}-x+1 / 2,-y+1 / 2, z+1 / 2 ;{ }^{e} x, y+1, z ;{ }^{\dagger}-x,-y,-z+1$} \\
\hline
\end{tabular}




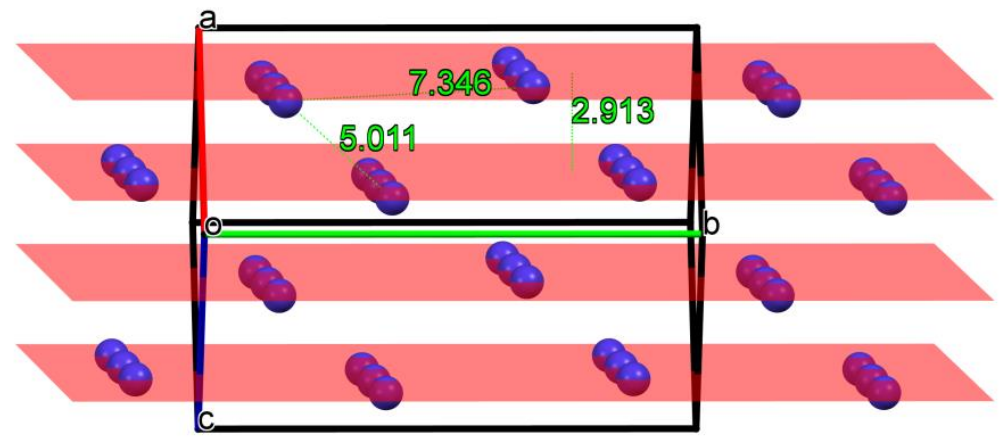

Figure S4 - Mercury representation of the layer stacking viewed down crystallographic [110] direction generated from CCDC UNAFOE02 $1 \mathrm{CIF}$ file of a tetra-aqua analogue of $\mathrm{Co}^{2+}$ (reference 31). The layer separation and the closest intra- and inter layer metal-metal separation is given. 